\title{
Platelets Mediate Neutrophil-dependent Immune Complex Nephritis in the Rat
}

Richard J. Johnson, Charles E. Alpers, Pam Pritzl, Matthias Schulze, Patricia Baker, Charles Pruchno, and William G. Couser Division of Nephrology, Department of Medicine and the Department of Pathology, University of Washington, Seattle, Washington 98195

\begin{abstract}
Neutrophils and platelets are frequently present in glomeruli in immune glomerulonephritis (GN). No role for the platelet in acute neutrophil-mediated renal injury has been defined. We investigated a neutrophil-mediated model of subendothelial immune complex GN in the rat. Rats were platelet-depleted (mean platelet $<10,000 / \mu$ l) with goat anti-platelet IgG before induction of GN by the renal artery perfusion of concanavalin A followed by anti-concanavalin A IgG. Platelet-depletion resulted in a significant reduction in albuminuria ( $7 \pm 2$ vs. $55 \pm 10$ $\mathrm{mg} / 24 \mathrm{~h})$ and fractional albumin excretion (0.045 \pm 0.01 vs. $0.410 \pm 0.09)$ compared with controls. The decrease in albuminuria was not due to differences in blood or glomerular neutrophil counts, complement, renal function, or glomerular antibody binding. Platelet-depleted rats had equivalent subendothelial deposits and glomerular endothelial cell injury but had minimal platelet infiltrates and fibrin deposition compared with controls. These studies demonstrate a role for platelets in mediating acute neutrophil-induced glomerular injury and proteinuria in this model of GN.
\end{abstract}

\section{Introduction}

Neutrophils and platelets are the dominant inflammatory cells at sites of injury in the initial phase of various immunologically mediated diseases, including the Arthus and Shwartzman reaction, hyperacute transplant rejection and some forms of passive cutaneous anaphylaxis (1-3). Although studies performed in the Arthus reaction suggest that it is neutrophil mediated but platelet independent $(4,5)$, most of these diseases appear to be mediated by both neutrophils and platelets $(1,3,6-8)$. In addition, platelet depletion has been reported to reduce neutrophil-mediated lung injury in both the mouse and rat after systemic complement activation $(9,10)$.

Neutrophils and platelets or their antigens have also been demonstrated in association with each other in various animal and human glomerular diseases (11-13). The coexistence of neutrophils and platelets has been particularly noted in systemic lupus erythematosus (SLE) with subendothelial immune complex (IC) ${ }^{1}$ deposits $(12,13)$. Despite the presence of both

Presented in part at the 20th Annual Meeting of the American Society of Nephrology in Washington, DC, December 1987.

Address reprint requests to Dr. Johnson, Division of Nephrology, Mail Stop RM-1 1, University of Washington, Seattle, WA 98195.

Received for publication 1 February 1988 and in revised form 4 May 1988.

1. Abbreviations used in this paper: Anti-Con A, rabbit anti-concanavalin A IgG; APS, goat anti-rat platelet IgG; $\mathrm{C}_{\text {creat }}$, creatinine clearance;

J. Clin. Invest.

(C) The American Society for Clinical Investigation, Inc.

$0021-9738 / 88 / 10 / 1225 / 11 \$ 2.00$

Volume 82, October 1988, 1225-1235 neutrophils and platelets in this disease, the role of platelets in mediating SLE and other types of glomerulonephritis (GN) has not been well studied.

Our interest in neutrophil-platelet interactions was initiated by our observations of the glomerular injury that results from one of the major cytotoxic mechanisms of the neutrophil, i.e., the myeloperoxidase (MPO)-hydrogen peroxide $\left(\mathrm{H}_{2} \mathrm{O}_{2}\right)$-halide system (14). When the renal artery of rats is perfused with the neutrophil enzyme MPO and its substrates $\mathrm{H}_{2} \mathrm{O}_{2}$ and chloride, severe glomerular endothelial cell injury and proteinuria results, and this is associated with marked platelet infiltration and activation $(14,15)$.

We have also studied a model of immune complex nephritis in the rat that is neutrophil mediated and associated with subendothelial deposits (16), thus resembling diffuse proliferative lupus nephritis or type I membranoproliferative GN in man. In this model as well, evidence for participation of the MPO- $\mathrm{H}_{2} \mathrm{O}_{2}$-halide system has been provided and platelets can be frequently demonstrated within glomeruli and adherent to deposits (16).

We now report on the effects of platelet depletion in this neutrophil-dependent model of subendothelial immune complex nephritis. The evidence presented here demonstrates a critical requirement for platelets for the development of acute glomerular injury.

\section{Methods}

Description of immune complex GN model. Immune complex GN was induced in rats by the selective renal artery perfusion of concanavalin A (Con A) followed by anti-concanavalin A (anti-Con A) antibody (16). This is a modification of the model originally described by Golbus and Wilson (17), and is based on the ability of the lectin Con A to bind to glycoproteins present in the glomerular capillary wall and hence function as a "planted" antigen. The subsequent perfusion of anti-Con A antibody results in in situ immune complex formation and is characterized by subendothelial immune deposits, complement activation, and platelet and neutrophil infiltration $(16,17)$. The model is also associated with varying degrees of fibrin deposition, and occasionally segmental necrosis of capillary loops.

Renal artery perfusion. Male Sprague-Dawley rats (Tyler Laboratories, Bellevue, WA and Charles River Breeding Laboratories, Wilmington, MA) between 200 and $330 \mathrm{~g}$ were anesthetized with chloral hydrate $(0.1 \mathrm{ml}$ of $3.6 \%$ solution per $10 \mathrm{~g}$ body wt i.p.). A midline incision was then made, and a left nephrectomy performed. The aorta was then exposed above and below the right renal and superior mesen-

$\mathrm{CH}_{50}$, titer for $50 \%$ lysis of antibody coated sheep erythrocytes by complement; $\mathrm{EM}$, electron microscopy; $\mathrm{FE}_{\mathrm{alb}}$, fractional excretion of albumin; GBM, glomerular basement membrane; $\mathrm{GN}$, glomerulonephritis; $\mathrm{H}_{2} \mathrm{O}_{2}$, hydrogen peroxide; IC, immune complex; IF, immunofluorescence; MPO, myeloperoxidase, PAF, platelet activating factor; PDGF, platelet-derived growth factor; PF4, platelet factor 4; RCD, Ringer's citrate dextrose; TXA $\mathbf{A}_{2}$, thromboxane $\mathrm{A}_{2}$. 
teric arteries, which lie opposite each other on the aorta. Renal artery blood flow was then interrupted by clamping the aorta at these locations, and the kidney was perfused by cannulating the superior mesenteric or left renal artery in a retrograde manner using a 30-gauge needle, with the aid of a dissecting microscope (Reichert Scientific Instruments, Buffalo, NY).

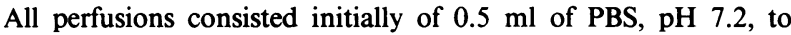
displace any blood remaining in the kidney. The kidney was then perfused with $1.0 \mathrm{ml}$ of PBS containing $125 \mu \mathrm{g}$ Con A (ICN Biomedicals, Costa Mesa, CA) that was determined using an extinction coefficient $\left(E^{1 \%}\right)$ of 12.8 for Con A. After the Con A perfusion, the cannula was cleared with $0.2 \mathrm{ml} \mathrm{PBS}$, and then $19 \mathrm{mg}$ of anti-Con A IgG in 0.5 $\mathrm{ml}$ PBS was infused, followed by $0.2-0.3 \mathrm{ml}$ PBS. All perfusions were performed using a constant infusion pump (Sage Instruments Division, Orion Research Inc., Cambridge, MA) at a rate of $0.5 \mathrm{ml} / \mathrm{min}$ on a heated operating table. After the perfusion the aorta was unclamped and blood flow was immediately restored to the kidney. Total ischemia time was always $<8 \mathrm{~min}$. The needle was then removed and the bleeding was stopped by applying gelfoam (Upjohn Co., Kalamazoo, MI) and/or cyanoacrylate adhesive (Borden Inc., Columbus, OH). In some platelet-depleted rats bleeding was difficult to stop, and these animals were excluded from analysis. In the remainder of the animals (both platelet depleted and control), hemostasis could be adequately achieved with total blood loss generally $<2 \mathrm{ml}$. The abdominal wound was then closed and the rat was placed under a heat lamp for $1-2 \mathrm{~h}$.

Experimental design. Two groups of 14 rats were studied. One group was platelet-depleted before induction of immune complex GN. This was accomplished by administering between 40 and $50 \mathrm{mg}$ of goat anti-rat platelet IgG (APS) per $100 \mathrm{~g}$ body wt i.p. 14 to $21 \mathrm{~h}$ before surgery and induction of GN. This dose of APS resulted in severe thrombocytopenia (mean platelet count $<10,000 / \mu$ l blood) within $8 \mathrm{~h}$ of administration and maintained mean platelet counts $<10,000 / \mu \mathrm{l}$ for a 24-h period after the induction of $\mathrm{GN}$. The control group received equivalent doses of normal goat IgG within the same time period before renal artery perfusions.

Blood samples were collected from the tail vein before injection of APS or normal goat IgG (pre) and again immediately before surgery at the time of disease induction $(t=0)$. After surgery rats were housed in metabolic cages with free access to water and the urine was collected overnight (14-20 h). A blood sample was then obtained via a cardiac puncture, the kidney was biopsied for histologic studies, and the rat was killed by ether inhalation. In some rats quantitative glomerular antibody binding studies were performed as outlined below.

Preparation of anti-Con $A$ antibody. New Zealand white rabbits ( $R$ \& R, Stanwood, Washington) were immunized with Con $A$ as previously described (16). Antibody activity of sera was determined by analysis of precipitin formation in microouchterlony plates. Sera with titers of 1:32 or greater were pooled and an IgG-enriched fraction was prepared by the caprylic acid method (18). After precipitation the supernatant containing IgG was dialyzed extensively against PBS at $4^{\circ} \mathrm{C}$ and then stored at $-20^{\circ} \mathrm{C}$. The protein content was determined spectrophotometrically using an extinction coefficient $\left(E^{1 \%}\right)$ of 14.0 .

Preparation of APS. APS was raised in a goat (Triple J Farms, Redmond, WA). For each immunization blood was collected via a cardiac puncture from one or two Sprague-Dawley rats in $40 \mathrm{mM}$ EDTA. The blood was then diluted with an equal volume of Ringer's

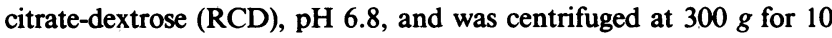
min to obtain platelet-rich plasma. The upper two-thirds of plasma was collected and again centrifuged at $800 \mathrm{~g}$ for $10 \mathrm{~min}$. The platelet pellet was then washed with RCD to remove any serum and resuspended in $2.0 \mathrm{ml}$ of RCD. Cytospin preparations of the pellet showed minimal $(<5 \%)$ contamination with erythrocytes. The suspension was then mixed with equal volumes of complete Freund's adjuvant (Difco, Detroit, MI) for the initial injection and was administered intramuscularly and subcutaneously. Repeated immunizations were performed using incomplete Freund's adjuvant (Difco) at 4, 12, and 20 wk after the initial injection. The number of platelets used per immunization varied from 1-6 $\times 10^{9}$ platelets. Plasma was collected by plasmapher- esis 1-2 wk after the second through fourth immunizations and was pooled. An IgG enriched fraction was prepared using caprylic acid, and the antibody was dialyzed against PBS, concentrated and the protein content determined using the $\mathrm{E}^{1 \%}$ of 14.0.

An intraperitoneal dose in the rat of 40 to $50 \mathrm{mg}$ of APS per $100 \mathrm{~g}$ body wt resulted in severe thrombocytopenia with platelet counts $<10,000 / \mu \mathrm{l}$ within $8 \mathrm{~h}$. This degree of platelet depletion was maintained for 36-48 $\mathrm{h}$. This dose of APS did not affect hematocrit, neutrophil counts, serum C3 levels, or serum creatinine when measured 24-26 $\mathrm{h}$ postinjection.

Because the administration of APS intravenous has been reported to cause significant hemodynamic impairment (19) we injected APS intraperitoneally. Six rats injected intraperitoneally with APS had systolic blood pressures measured before APS injection and at 2, 6, and 24 $\mathrm{h}$ later. Blood pressure was measured after induction of light anesthesia with ether using a tail cuff connected to a pressure transducer and recorded with a plethysmograph (Narco Biosystems, Houston, TX). Blood pressure in these rats remained unchanged at all times studied with the mean systolic BP always in excess of $100 \mathrm{mmHg}$.

Studies performed in vitro demonstrated that APS reacted against normal rat serum with a titer of $1: 2$ on microouchterlony plates. APS also caused agglutination of erythrocytes at a titer of 1:20 but did not result in discernible hemolysis when injected into normal animals. APS was also tested for its ability to band rat PMNs and macrophages. Rat PMNs were collected from the peritoneal cavity of normal rats 3-4 h after i.p. injection with $0.1 \%$ oyster glycogen (Sigma Chemical Co. St. Louis, MO) and were $>95 \%$ pure as assessed by Wright's stain. Rat macrophages were harvested from peritoneal exudate $4 \mathrm{~d}$ after the injection of 3\% thioglycollate i.p. (Difco) (20). The macrophages were grown overnight in RPMI with $10 \%$ fetal calf serum and $15 \mathrm{mM}$ Hepes buffer (Gibco Laboratories, Santa Clara, CA), and were $>95 \%$ pure as assessed by the uptake of neutral red. Rat platelets $\left(5 \times 10^{7} /\right.$ well), PMNs $\left(10^{5} /\right.$ well $)$ and macrophages $\left(10^{5} /\right.$ well $)$ were added to poly-L-lysine (Sigma Chemical Co.) coated 96-well plates (Nunc, Roskilde, Denmark). The cells were blocked with $2 \%$ BSA (Sigma Chemical Co.) and fixed with $2 \%$ paraformaldehyde. They were then blocked with $2 \%$ BSA, $0.1 \mathrm{M}$ glycine in PBS, $3 \% \mathrm{H}_{2} \mathrm{O}_{2}$ in cold methanol, and normal rabbit IgG (Calbiochem-Behring Corp., San Diego, CA). After washing with PBS, the cells were incubated with various dilutions of APS or normal goat IgG. After extensive washing the presence of goat IgG was determined using a biotinylated rabbit anti-goat IgG (Vector Laboratories, Burlingame, $\mathrm{CA}$ ) followed by avidin peroxidase (ABC Kit, Vector Laboratories), and developed with $O$-phenylene-diamine (Sigma Chemical Co.). The reaction was stopped after $5 \mathrm{~min}$ with $4.5 \mathrm{M}$ $\mathrm{H}_{2} \mathrm{SO}_{4}$ and was read at $492 \mathrm{~nm}$. All measurements were done in quadruplicate. Rat platelets reacted strongly with APS, and a dilution of 1:20,000 (i.e., $3.7 \mu \mathrm{g} / \mathrm{ml}$ ) had slightly greater reactivity than $1: 500$ dilution of normal goat $\mathrm{IgG}$ (i.e., $130 \mu \mathrm{g} / \mathrm{ml}$ ). In contrast, rat PMNs and macrophages reacted no stronger with APS than normal goat IgG.

Measurements. Platelet counts were determined by phase microscopy after lysis of erythrocytes with $1 \%$ ammonium oxalate. Hematocrit and white cell counts were determined by standard hematologic techniques, and white cell differentials were determined from blood smears stained with Diff-Quik (American Scientific Products, McGaw Park, IL). Plasma samples were assayed for creatinine using the picric acid method (Worthington Diagnostics, Freehold, NJ). Plasma albumin was measured with bromcresol green using an autoanalyzer (21). Plasma C3 levels were measured by radial immunodiffusion (22) and quantitated in each rat as a percentage of its baseline (i.e., pre) $\mathrm{C} 3$ level. The titer of heparinized plasma that results in lysis of $50 \%$ of sheep erythrocytes that are coated with rabbit anti-sheep erythrocyte IgG (Diamedix, Miami, FL) $\left(\mathrm{CH}_{50}\right)$ was measured using standard methodology (23). Urine total protein was measured using the sulfosalicylic acid method (24). Urine albumin was measured in 96-well microtiter plates (Dynatech, Alexandria, VA) by an ELISA method using a sheep anti-rat albumin (0.3 $\mu \mathrm{g} /$ well) (Organon Teknika Corp., BCA Cappel, West Chester, PA) as the coating antibody and a peroxidase-labeled sheep anti-rat albumin ( $2 \mu \mathrm{g} /$ well; Organon Teknika Corp.) as the 
detecting antibody (20). The presence of detecting antibody was determined after incubation with $0.2 \mathrm{mM} \mathrm{2,2'-azino-di-(3-ethylbenzthiazo-}$ line-sulfonate) (ABTS) (Boehringer Mannheim, Indianapolis, IN) and $2.5 \mathrm{mM} \mathrm{H}_{2} \mathrm{O}_{2}$ in $100 \mathrm{mM}$ acetate buffer at $\mathrm{pH} 5.0$, and was measured spectrophotometrically at $405 \mathrm{~nm}$, using a Dynatech MR 560 microplate reader (Dynatech). The ELISA method was standardized using samples that had also been assayed for albumin using the autoanalyzer method.

Glomerular antibody binding of anti-Con A. To insure that glomerular binding of anti-Con A antibody was not altered by platelet depletion, glomerular antibody binding of anti-Con A was determined using a double-label method (25). Briefly, control rats or platelet-depleted rats had GN induced as described above except that the antiCon A was trace-labeled with ${ }^{125} \mathrm{I}$ by the chloramine T method (26). Rats were then placed in metabolic cages for urine collection for a mean of 15 to $16 \mathrm{~h} .1 \mathrm{~h}$ before sacrifice rats received $10 \mu \mathrm{g}{ }^{131} \mathrm{I}$-rat IgG as a blood marker. At sacrifice the kidney was removed, and glomeruli were isolated from the cortex using differential sieving techniques (26). Glomeruli were counted visually with a Fuchs-Rosenthal counting chamber (Hausser-Scientific Co., Blue Bell, PA) and specific glomerular deposition of ${ }^{125} \mathrm{I} \mathrm{IgG}$ determined using a Prias autogamma counter (Packard Instrument Co., Downers Grove, IL) as described elsewhere (26). Briefly, the specific glomerular uptake of ${ }^{125} \mathrm{I}$-anti-Con A was calculated using the formula: Specific glomerular ${ }^{125} \mathrm{I}$-anti-Con A uptake $=G^{125} I-G^{131} I\left[\frac{B^{125} I}{B^{131} I}\right]$, where $G^{125} I$ and $G^{131} I$ are counts per minute of ${ }^{125} I$ and ${ }^{131} I$ in an aliquot of glomeruli and $B{ }^{125} I$ and $B{ }^{131} I$ are counts per minute of ${ }^{125} \mathrm{I}$ and ${ }^{131} \mathrm{I}$ in $1 \mathrm{ml}$ of whole blood (26). Counts per minute of ${ }^{125} \mathrm{I}$-anti-Con $\mathrm{A}$ were converted to $\mu \mathrm{g}$ total antiCon A antibody per 38,000 glomeruli (the average number of glomeruli present in a rat kidney [27]) based on the specific activity of ${ }^{125} \mathrm{I}$ anti-Con A preparations.

Renal histology. Tissue for light microscopy was initially fixed in Sorensen's buffered formalin (10\% formalin in $0.1 \mathrm{M} \mathrm{Na}$ phosphate buffer, pH 7.2) for at least $4 \mathrm{~h}$, and was then dehydrated in graded ethanols and embedded in glycomethylmethacrylate (Polysciences, Warrington, PA) (15). 2- $\mu$ m sections were stained with periodic acid Schiff reagent.

The number of neutrophils present per glomerular cross-section was counted by two observers without knowledge of whether the biopsy was from a platelet-depleted or control rat. 10 glomeruli were examined per rat, and the average number of neutrophils per glomerulus was calculated. Glomerular cross-sections containing only a minor portion of the glomerular tuft $(<20$ discrete capillary segments per cross-section) were not utilized in obtaining neutrophil counts.

Tissue for immunofluorescence (IF) was embedded in O.C.T. (Lab-Tek Products, Miles Laboratories, Naperville, IL) and snap-frozen in isopentane (28). Con A was detected by indirect IF using a biotinylated goat anti-Con A antibody followed by FITC-conjugated strep-avidin (Amersham, Arlington Heights, IL). Rabbit anti-Con A IgG was detected using FITC-conjugated goat anti-rabbit IgG, rat C3 with FITC-conjugated goat anti-rat C3, and rat fibrin with FITC-conjugated goat anti-rat fibrinogen. The presence of rat $\mathrm{C} 5 \mathrm{~b}-9$ was determined using a biotinylated mouse antirat C $5 \mathrm{~b}-9$ monoclonal antibody that had been previously prepared in our laboratory, ${ }^{2}$ followed by FITC-strep-avidin. Sections were examined with a Leitz Ortholux II microscope with a Ploempak 2.2 vertical fluorescence illuminator (E. Leitz, Inc., Rockleigh, NJ). The intensity of fluorescence was graded semiquantitatively from 0 to $4+$ as described previously (28). In evaluating fibrin deposition the following scale was used: 0 , fibrin deposition absent; $1+$, up to $25 \%$ of capillary loops demonstrated fibrin; $2+$, up to $50 \%$ of capillary loops demonstrated fibrin; 3 , up to $75 \%$ of capillary

2. Schulze, M., P. J. Baker, D. T. Perkinson, R. J. Johnson, R. F. Ochi, R. A. K. Stahl, and W. G. Couser. Manuscript submitted for publication. loops demonstrated fibrin; 4 , up to $100 \%$ of capillary loops demonstrated fibrin.

Tissue for electron microscopy (EM) was fixed in half-strength Karnovsky's solution (1\% paraformaldehyde and $1.25 \%$ glutaraldehyde in $0.1 \mathrm{M} \mathrm{Na}$ cacodylate buffer, $\mathrm{pH} 7.0$ ). After fixation, tissue was postfixed in $1 \%$ osmium tetroxide for $2 \mathrm{~h}$, dehydrated in graded ethanols, and embedded in epoxy resin. Thin sections were stained with uranyl acetate and lead acetate and examined with a Philips 410 (Philips Export BV, Eindhoven, The Netherlands) electron microscope.

Analysis of data. All values expressed are mean \pm SE. Comparisons between groups were made utilizing either the Student's $t$ test or the Wilcoxon rank sum test (29).

\section{Results}

Induction of thrombocytopenia with APS. The administration of APS resulted in severe thrombocytopenia (mean platelet $<10,000 / \mu \mathrm{l})$ that was maintained from the time of induction of immune complex GN until the time of sacrifice $24 \mathrm{~h}$ later (Table I). Control rats also had a substantial fall in their platelet counts $(\sim 60 \%)$ after induction of $\mathrm{GN}$, possibly reflecting platelet consumption secondary to the disease process $(\mathrm{Ta}$ ble I).

Both control and APS-treated rats developed a mild neutrophilia after injection with IgG or APS, respectively. However, there were no differences in neutrophil counts between groups. Platelet-depleted rats did have a slightly higher total white cell count at sacrifice $(P<0.02$; Table I).

Hematocrit levels fell in the platelet-depleted rats from the time of surgery and disease induction until sacrifice $(P$ $<0.001)$. The fall in hematocrit was primarily due to slow and persistent bleeding during the postoperative period in plateletdepleted animals.

Effect of platelet-depletion on glomerular antibody binding. Glomerular antibody binding was quantitated in seven platelet-depleted and eight control rats with immune complex GN. Platelet depletion did not alter glomerular binding of anti-Con A IgG at $24 \mathrm{~h}$ after induction of GN (162 $19 \mu \mathrm{g}$ anti-Con A $\mathrm{IgG} / 38,000$ glomeruli in APS-treated rats vs. $165 \pm 18 \mu \mathrm{g}$ antiCon A IgG/38,000 glomeruli in controls, $P=\mathrm{NS}$ ), indicating

Table I. Hematologic Values in PD $(n=14)$ and Control (c) Rats $(n=14)$ with Immune Complex $G N$

\begin{tabular}{llccc}
\hline & & \multicolumn{3}{c}{ Time } \\
\cline { 3 - 5 } & & Pre & $0 \mathrm{~h}$ & $24 \mathrm{~h}$ \\
\hline \multirow{2}{*}{ HCT } & PD & $42 \pm 1$ & $42 \pm 1$ & $26 \pm 1^{*}$ \\
& C & $42 \pm 1$ & $42 \pm 1$ & $42 \pm 2$ \\
WBC & PD & $13.8 \pm 1.4$ & $17.8 \pm 1.1$ & $14.2 \pm 1.3^{\ddagger}$ \\
& C & $15.7 \pm 1.4$ & $17.1 \pm 1.6$ & $10.3 \pm 0.9$ \\
PMN & PD & $1.90 \pm 0.29$ & $6.47 \pm 0.70$ & $3.98 \pm 0.63$ \\
& C & $2.65 \pm 0.60$ & $5.28 \pm 0.98$ & $4.27 \pm 0.53$ \\
PLT & PD & $681 \pm 74$ & $2 \pm 1^{*}$ & $6 \pm 2^{*}$ \\
& C & $629 \pm 45$ & $630 \pm 44$ & $245 \pm 67$
\end{tabular}

Hematologic values are shown for platelet-depleted $(P D)$ and control $(C)$ groups before injection of antiplatelet serum or normal goat IgG (pre), at the time of surgery and induction of $\mathrm{GN}(t=0)$, and at the time of sacrifice $24 \mathrm{~h}$ later $(t=24)$. Data shown mean values \pm SEM. ${ }^{*} P<0.001,{ }^{\ddagger} P<0.02$, relative to control group. 
that glomerular deposition of antibody was equivalent in the control and platelet-depleted groups.

Effect of platelet-depletion on histology. Control rats with immune complex GN $(n=14)$ developed a severe proliferative nephritis with prominent neutrophil and mononuclear cell infiltration at $24 \mathrm{~h}$ (Fig. 1). Most glomeruli have significant intracapillary thrombus formation, and occasional segmental necrosis of capillary loops.

Platelet-depleted rats had more infiltrating neutrophils in glomeruli than control rats at $24 \mathrm{~h}(7.6 \pm 0.9 \mathrm{PMNs} /$ glomerular cross-section vs. $3.5 \pm 0.5 \mathrm{PMNs}$ /glomerulus, $P<0.001)$. Platelet depletion was also associated with a dramatic diminution of intracapillary thrombi and segmental necrosis (Fig. 1). The reduction in glomerular thrombosis in platelet depleted rats may have allowed increased access of neutrophils to capillary lumina accounting for the higher glomerular neutrophil counts in APS-treated animals. The presence of clots in the capillary lumina in control rats also resulted in considerable cell compression and distortion of intraluminal cells, which made identification of neutrophils more difficult.

IF showed that there appeared to be no differences in platelet-depleted and control rats with immune complex GN in glomerular deposits of Con A antigen, rabbit IgG, rat C3, and rat C5b-9 at $24 \mathrm{~h}$ after disease induction. Staining for Con $\mathrm{A}$ antigen was $2-3+$, rabbit IgG $3-4+$, rat C3 $2-3+$, and rat C5b-9 was trace to $1+$. However, there were differences noted in fibrin deposition. Control rats had fibrin deposition in 50 to $75 \%$ of most capillary loops, whereas platelet-depleted rats had minimal ( $<25 \%$ ) fibrin deposition (Fig. 2).

Electron microscopy of glomeruli from control rats with immune complex GN demonstrated a dense band of subendothelial deposits associated with endothelial cell denudation and focal epithelial cell foot process fusion (Fig. $3 \mathrm{~A}$ ). Subepithelial deposits were present focally. Platelets and neutrophils could frequently be demonstrated adherent to the subendothelial deposits, and fibrin and platelet aggregates were present
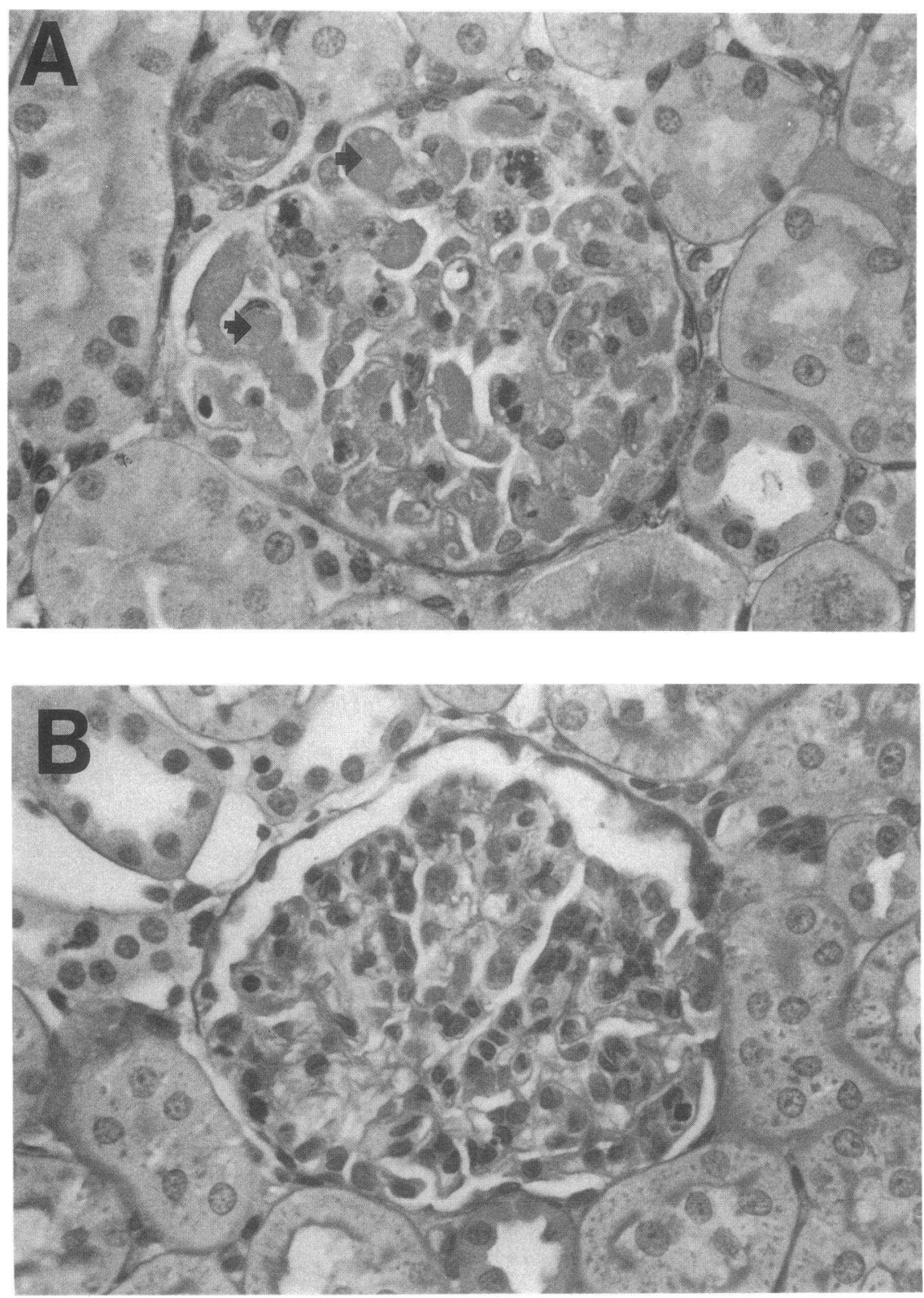

Figure 1. Light microscopy of a representative glomerulus from a control rat $(A)$ and a platelet-depleted rat $(B) 24 \mathrm{~h}$ after renal artery perfusion of Con A and anti-Con A IgG. Both control and platelet-depleted rats have prominent neutrophil infiltrates, but only the control animals had marked fibrin thrombi (arrows) (periodic acid Schiff stain, $\times 400$ ). 

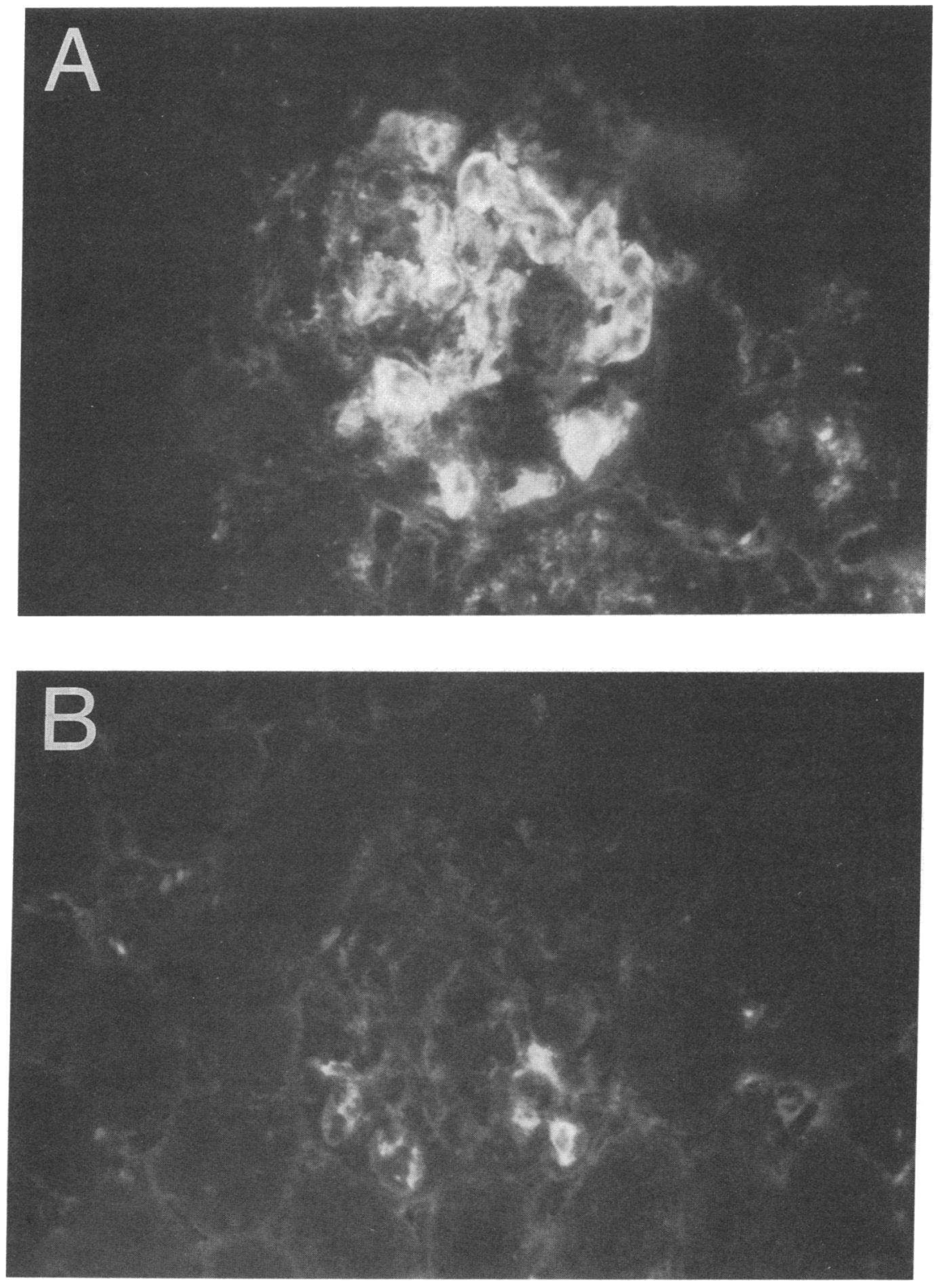

Figure 2. Immunofluorescent staining for fibrinogen in control $(A)$ and platelet-depleted $(B)$ rats $24 \mathrm{~h}$ after induction of $\mathrm{GN}$ with Con $\mathrm{A}$ and anti-Con $\mathrm{A}$ IgG. Whereas the control rats had marked fibrin deposition $(A)$, the platelet-depleted rats had fibrin in $<25 \%$ of capillary loops $(\times 400)$. within capillary loops (Figs. 3 and 4). Rats that were plateletdepleted also had subendothelial and focal subepithelial deposits associated with endothelial cell injury and neutrophil infiltration (Fig. 5). However, there was a marked reduction in platelet infiltration and fibrin deposition, and only minimal epithelial cell foot process fusion. Animals in both groups showed ultrastructural evidence of neutrophil activation, characterized by pseudopodia formation, degranulation and the presence of intracytoplasmic phagocytic vacuoles. Neutrophils in platelet-depleted rats appeared to have more extensive degranulation, but there was considerable overlap in this parameter between the two groups, and even within neutrophils present in individual animals in each group.

Effect of platelet-depletion on urine protein excretion and renal function. Platelet-depleted rats with immune complex GN had significantly lower total urine albumin excretion in the first $24 \mathrm{~h}$ after disease induction than control rats $(6.8 \pm 1.7$ vs. $54.6 \pm 10.0 \mathrm{mg} / \mathrm{d}$, Table II, $P<0.001$ ). In four platelet-de- pleted rats protein excretion was also quantitated on days $1-2$. Two rats that maintained platelet counts of $<15,000 / \mu 1$ through days 1-2 continued to excrete $<20 \mathrm{mg}$ of protein, whereas two rats that had been adequately platelet depleted on days $0-1$ but whose platelet counts had risen to 100,000 and $122,000 / \mu$ l on days $1-2$ had protein excretions of 107 and 133 $\mathrm{mg} / \mathrm{d}$, respectively. These latter results are similar to the $112 \pm 10 \mathrm{mg} / \mathrm{d}$ of proteinuria that we had previously reported for days 1-2 in control rats with Con A anti-Con A GN (16).

To exclude an effect of glomerular filtration rate or serum albumin concentration on urinary albumin excretion in the platelet-depleted and control rats with GN, fractional excretion of albumin $\left(\mathrm{FE}_{\mathrm{alb}}\right)$ was measured. As shown in Table II, $\mathrm{FE}_{\text {alb }}$ was significantly lower in platelet-depleted rats with Con A anti-Con A GN $(P<0.001)$. In contrast, no differences in creatinine clearances $\left(\mathrm{C}_{\text {creat }}\right)$ or serum creatinines were noted in APS-treated and control rats. Urine volumes, however, were greater in platelet-depleted versus control rats $(P<0.02$, Table 


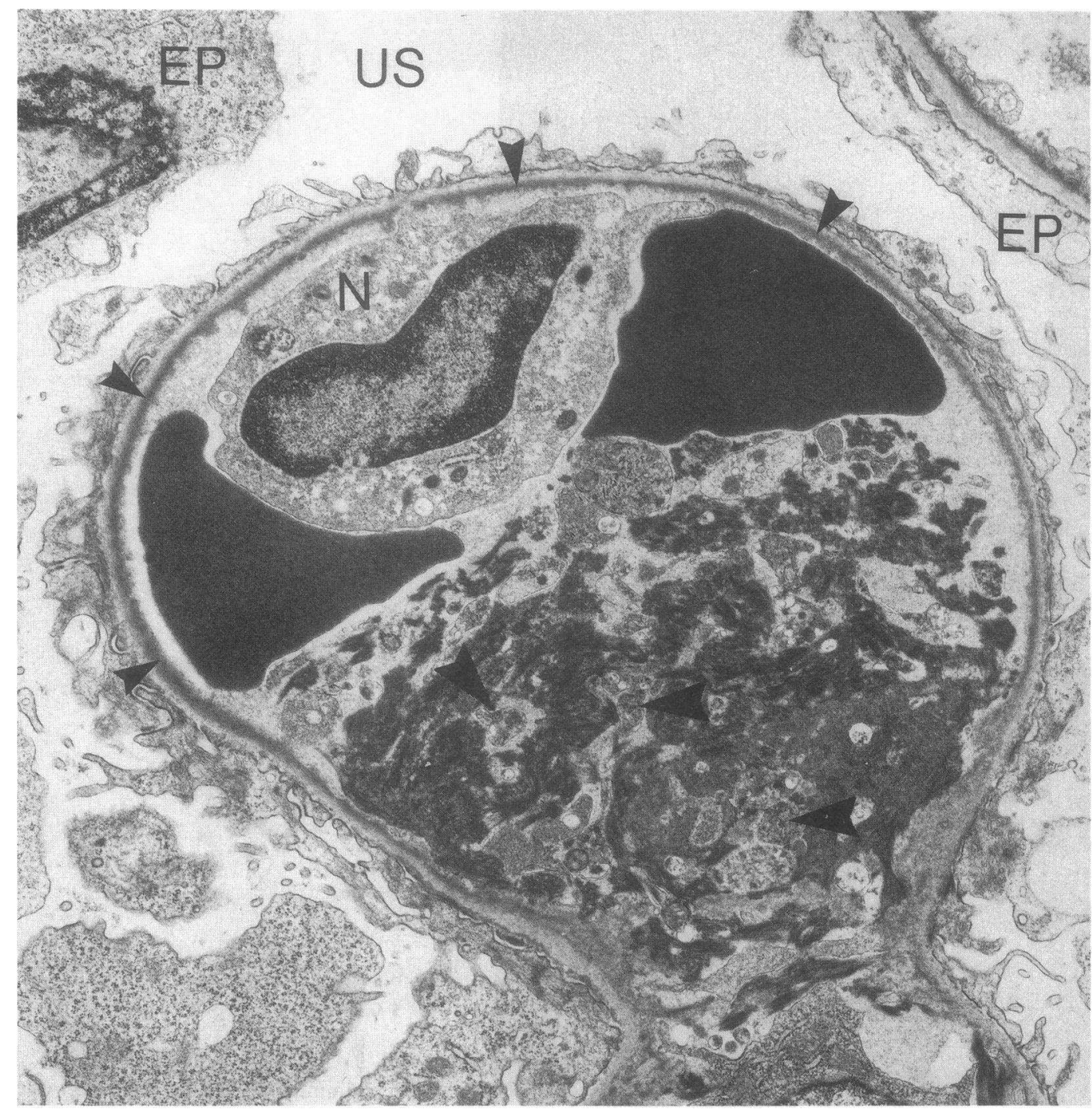

Figure 3. Typical glomerular capillary loop from a control rat $24 \mathrm{~h}$ after induction of GN with Con $A$ and anti-Con $\mathrm{A}$ IgG.

The capillary loop is occluded and contains an infiltrating neutrophil as well as a microthrombus composed of degranulated platelets (large arrowheads) and fibrin tactoids. The endothelium is denuded, and diffuse dense subendothelial deposits are present on the inner portion of the basement membrane (small arrowheads). Visceral epithelial cells show swelling of cell bodies, microvillus transformation, and partial effacement of foot process. (EP, epithelial cell; $N$, neutrophil; $U S$, urinary space) $(\times 10,200)$.

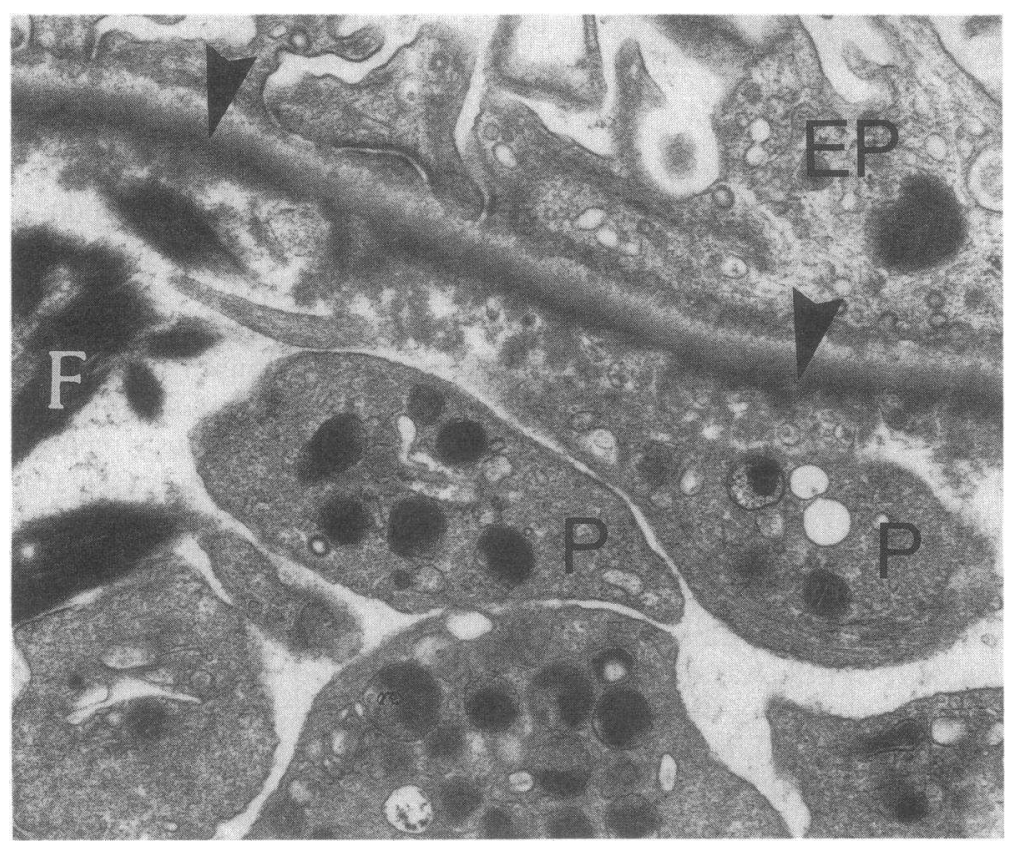

Figure 4. High power view of platelet aggregates and fibrin tactoids in a capillary lumen adjacent to the glomerular capillary wall in a control rat with Con A-anti-Con A GN. The endothelium is severely injured and mostly denuded; subendothelial deposits (arrowheads) are diffusely present ( $E P$, epithelial cell; $F$, fibrin; $P$, platelet) $(\times 19,300)$. 


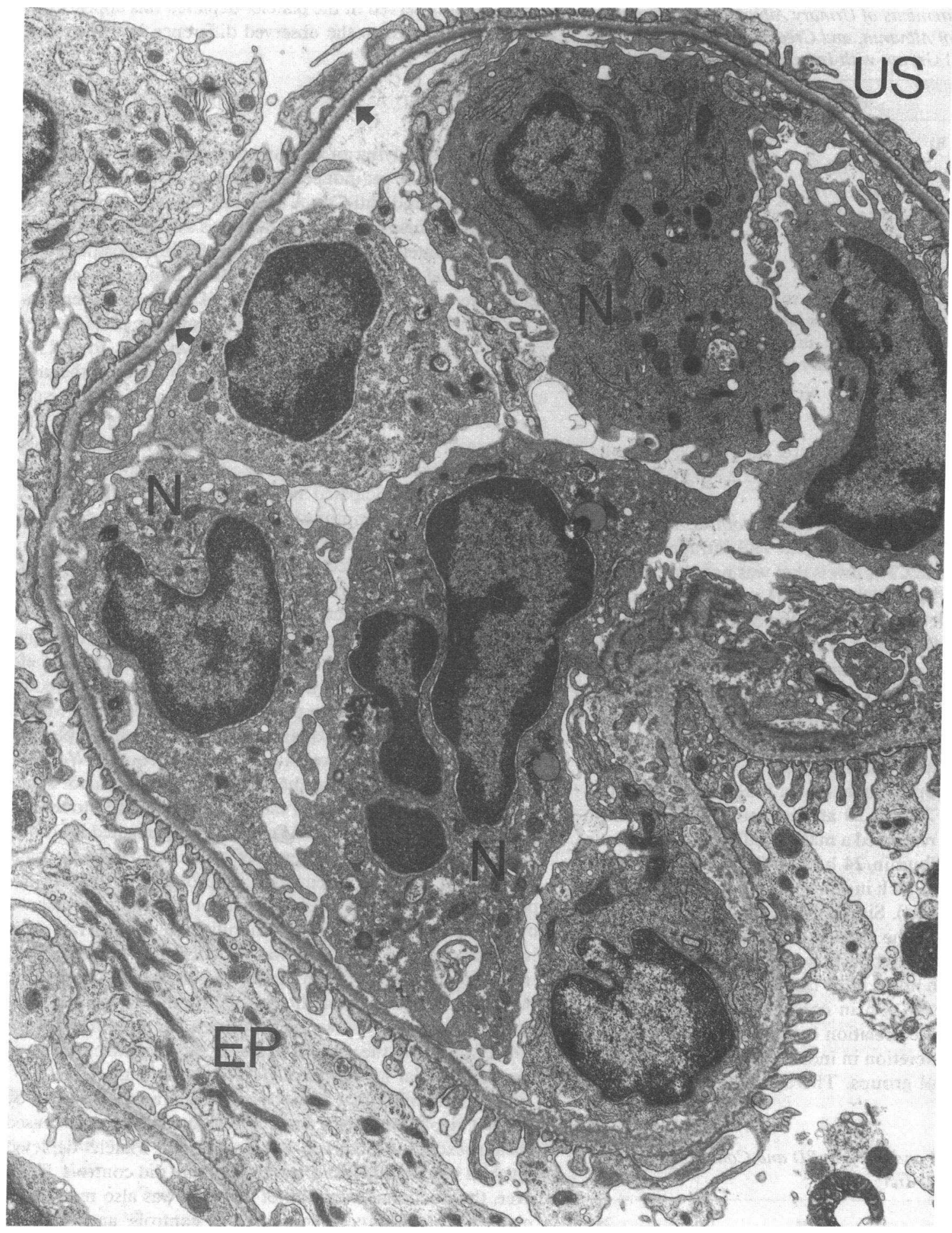

Figure 5. The glomerular capillary loop from a platelet-depleted rat $24 \mathrm{~h}$ after induction of GN with Con A and anti-Con IgG demonstrates numerous neutrophils within the lumen; no platelets or fibrin are present. The endothelium is focally denuded (arrows), but in other areas is intact. Epithelial cell foot processes remain well preserved. (EP, epithelial cell; $N$, neutrophil; $U S$, urinary space) $(\times 10,200)$.

II). Plasma albumin was lower in platelet-depleted rats at the time of surgery and induction of GN $(2.26 \pm 0.10$ vs. $2.64 \pm 0.23$ $\mathrm{g} / \mathrm{dl}$ in APS vs. control, $P<0.005)$ and at the time of sacrifice $(1.76 \pm 0.12$ vs. $2.17 \pm 0.07 \mathrm{~g} / \mathrm{dl}$ in APS vs. control, $P<0.02)$.

To exclude an effect of anemia on lowering the protein excretion (30) in the platelet-depleted rats, we induced immune complex GN in five additional rats that had been previously made anemic by repeated cardiac punctures. Despite having similar hematocrits as the platelet-depleted rats $24 \mathrm{~h}$ after induction of $\mathrm{GN}(26 \pm 1$ vs. $26 \pm 1, P=\mathrm{NS})$, the total 
Table II. 24-H Measurements of Urinary Albumin Excretion, Fractional Excretion of Albumin, and Creatinine Clearances in PD and Control (C) Groups with Immune Complex GN

\begin{tabular}{lccc}
\hline \multicolumn{1}{c}{ Measurement } & PD & $\mathrm{C}$ & $P$ value \\
\hline Urine albumin $(\mathrm{mg} / 24 \mathrm{~h})$ & $6.8 \pm 1.7$ & $54.6 \pm 10.0$ & $P<0.001$ \\
& $(n=12)$ & $(n=13)$ & \\
$\mathrm{FE}_{\text {Albumin }} \times 100^{*}$ & $0.045 \pm 0.01$ & $0.410 \pm 0.09$ & $P<0.001$ \\
$\mathrm{C}_{\text {creat }}(\mathrm{ml} /$ min per $100 \mathrm{~g})$ & $0.24 \pm 0.03$ & $0.19 \pm 0.02$ & $P=\mathrm{NS}$ \\
$\mathrm{U}_{\text {vol }}(24 \mathrm{~h})$ & $19.4 \pm 2.8$ & $10.5 \pm 1.8$ & $P<0.02$
\end{tabular}

* $\mathrm{FE}_{\text {albumin }}=\left(\mathrm{U}_{\text {alb }} \times \mathrm{P}_{\text {creat }}\right) /\left(\mathrm{U}_{\text {creat }} \times \mathrm{P}_{\mathrm{alb}}\right)$. Abbreviations: $\mathrm{C}_{\text {creat }}$, creatinine clearance; $F_{\mathrm{alb}}$, fractional excretion of albumin; $\mathrm{P}_{\mathrm{alb}}$, plasma albumin; $P_{\text {creat }}$, plasma creatinine; $U_{\text {alb }}$, urine albumin concentration; $U_{\text {creat }}$, urine creatinine concentration; $U_{v o l}(24 \mathrm{~h})$ corrected $24 \mathrm{~h}$ urine volume.

protein excretion in the anemic control rats was significantly greater than in the platelet-depleted rats $(93 \pm 23 \mathrm{mg} / \mathrm{d}$ vs. $15 \pm 2$ $\mathrm{mg} / \mathrm{d}, P<0.001)$.

Effect of platelet-depletion on plasma complement levels. The injection of APS and normal goat IgG intraperitoneally resulted in a decrease in $\mathrm{CH}_{50}$ levels that was noted at the time of induction of $\mathrm{GN}$ (Table III). Both $\mathrm{CH}_{50}$ and $\mathrm{C} 3$ levels were lower in platelet-depleted rats at the time of renal artery perfusion and induction of $\mathrm{GN}$ than in control rats $(P<0.001)$ but differences between the groups did not persist at $24 \mathrm{~h}$.

To exclude the possibility that the decrease in urine albumin excretion was secondary to this transient reduction in complement levels, a separate analysis was performed on a subset of rats from the control and platelet-depleted groups that had equivalent complement levels. When all rats that had $\mathrm{CH}_{50}$ titers between 20 and 29 at the time of $\mathrm{GN}$ induction were analyzed, there remained a marked difference in albumin excretion $(7 \pm 3 \mathrm{mg}$ albumin $/ 24 \mathrm{~h}$ in APS-treated rats $(n=6)$ vs. $76 \pm 14 \mathrm{mg}$ albumin $/ 24 \mathrm{~h}$ in control rats $(n=7), P<0.01$ by Wilcoxon-rank sum test). Similarly, if rats with $\mathrm{C} 3$ levels between 75 and $95 \%$ at the time of surgery were analyzed, a difference in protein excretion between platelet-depleted and control rats was again noted $[7 \pm 2 \mathrm{mg} / 24 \mathrm{~h}$ in APS-treated rats $(n=5)$ vs. $70 \pm 25 \mathrm{mg} / 24 \mathrm{~h}$ in controls $(n=4), P<0.05$ ]. Finally, there was no correlation between complement levels and urine albumin excretion in individual animals in plateletdepleted and control groups. Therefore, the depression of

Table III. Plasma C3 and $\mathrm{CH}_{50}$ in PD and Control (C) Groups with Immune Complex GN

\begin{tabular}{llccc}
\hline & & Pre & $0 \mathrm{~h}$ & $24 \mathrm{~h}$ \\
\hline $\mathrm{CH}_{50}$ (Titer) & PD & $52 \pm 4$ & $20 \pm 2^{*}$ & $24 \pm 2$ \\
& C & $48 \pm 5$ & $33 \pm 3$ & $26 \pm 3$ \\
C3 (\% of Pre value) & PD & $100 \%$ & $70 \pm 6^{*}$ & $60 \pm 11$ \\
& C & $100 \%$ & $104 \pm 7$ & $75 \pm 7$ \\
\hline
\end{tabular}

The values shown are for platelet-depleted $(P D)$ and control $(C)$ groups prior to injection of APS or normal goat IgG (pre), at the time of surgery and induction of $\mathrm{GN}(t=0)$, and at the time of sacrifice $24 \mathrm{~h}$ later $(t=24)$. Data show mean values $+\mathrm{SEM},{ }^{*} P<0.001$ relative to control group. complement observed in the platelet-depleted rats appears not to have contributed to the observed difference in urine albumin excretion.

\section{Discussion}

We have been studying an immune complex model of glomerulonephritis in the rat induced by the renal artery perfusion of Con $A$ antigen and anti-Con $A$ antibody. The model is characterized by a diffuse proliferative nephritis associated with neutrophil and platelet infiltration, marked fibrin deposition, and subendothelial immune complex deposits. Similar glomerular lesions are seen in severe lupus nephritis and type I membranoproliferative glomerulonephritis in man. Previous studies have demonstrated that depletion of neutrophils to $<250 /$ $\mathrm{mm}^{3}$ with antineutrophil serum significantly reduced the proteinuria and abolished the glomerular neutrophil infiltrate associated with this model (16). The role of platelets, which are so frequently associated with neutrophils in this model, has not been studied. This study addressed the question of whether these platelets participated in mediating the acute phase of neutrophil-induced immune injury or were simply present as a secondary response to tissue damage.

The findings reported here demonstrate that platelets are required for neutrophil-mediated injury to occur in this model. Specifically, selective depletion of platelets in the rat to $<10,000 / \mu 1$ abolished proteinuria, improved glomerular histology and markedly diminished fibrin deposition. These effects were independent of the amount of glomerular antibody bound and of alterations in plasma complement levels. Moreover, they could not be explained by any effect of antiplatelet IgG on circulating leukocytes or neutrophil counts. We have also been able to show that the antiplatelet IgG does not affect PMN function, as assessed by the ability of rat PMNs to release hydroxyproline from rat GBM containing aggregated IgG or to iodinate protein in the presence of opsonized zymosan (data not shown). Despite a reduction in proteinuria, platelet-depleted rats had even greater numbers of neutrophils observed by light microscopy within glomeruli than control rats with immune complex GN. This was probably due to the lack of intraglomerular thrombi in the platelet-depleted rats, thereby providing greater accessibility of neutrophils to the capillary lumina. However, this would have been expected to result in greater injury in the platelet-depleted rats if neutrophils were the only cellular mediators of glomerular damage.

The possibility that hemodynamic alterations induced by platelet depletion might have contributed to the decreased protein excretion observed was considered. Platelet-depleted rats had more blood loss after surgery than did controls. However, the fractional excretion of albumin was also reduced in platelet-depleted rats as compared to controls, and this corrects for differences in serum albumin and glomerular filtration rate (31). The urine volume was actually higher in the platelet-depleted rats, which further suggests that the blood loss did not result in significant volume depletion. Anemia has also been reported to decrease glomerular pressures and reduce proteinuria (30). However, in our studies rats with an equivalent degree of anemia had even more proteinuria than nonanemic controls. Thus platelets appear to play a direct role in neutrophil-mediated glomerular injury in this model.

Previous studies have suggested that platelets participate in some inflammatory glomerular diseases. Platelets and platelet 
antigens can be demonstrated morphologically in glomeruli of man and animals with various types of $\mathrm{GN}(11,13,32,33)$. In many glomerular diseases platelets are activated, and have undergone a partial release reaction as shown by elevated blood levels of platelet granule constituents (e.g., serotonin, platelet factor 4 [PF4]), and by evidence of depletion of these constituents within the platelets themselves (34). Studies using various anti-platelet agents have also demonstrated a reduction in injury in some animal models of GN $(35,36)$, as well as in membranoproliferative and mesangial proliferative $\mathrm{GN}$ in man $(37,38)$. However, previous studies of selective platelet depletion in experimental models of glomerular disease have not consistently confirmed a role for the platelet in mediating immune renal injury. In the neutrophil-independent model of acute serum sickness in rabbits platelet depletion had no effect in one study (19), whereas in another study platelet depletion resulted in decreased immune complex localization in glomeruli (39). Platelet depletion has also been reported to have no effect on the autologous phase of nephrotoxic nephritis in the rabbit (40), although another study reported that platelet depletion resulted in lower protein excretion for the first $3 \mathrm{~d}$ in the accelerated version of this same model (41). A likely explanation for why these prior studies have been inconclusive is that the models studied are not characterized by extensive neutrophil or platelet involvement as seen in the present model of immune complex GN. Studies by others have shown that the glomerular inflammatory reaction induced by immune deposits is dependent on the site as well as the mechanism of glomerular immune deposit formation with substantially more inflammatory cell involvement if immune deposits are formed adjacent to the capillary lumen as in the model studied here as opposed to deposit formation in an intramembranous or subepithelial location (42).

The mechanisms by which platelets localize in glomeruli in subendothelial immune complex nephritis have not been defined. Endothelial cell injury secondary to neutrophil or complement action could result in the release of platelet activating factor (PAF) (43). Neutrophils and mesangial cells can also produce PAF (reviewed in 44). Once the endothelium has been denuded, platelets could adhere to the subendothelial microfibrils and the collagen-rich glomerular basement membrane (GBM) (45). Platelets can also adhere to accessible immune complexes in the rat, perhaps via a $\mathrm{C} 3 \mathrm{~b}$ receptor mechanism (46).

The mechanism for the platelet-mediated increase in glomerular permeability observed in our studies was not defined in the experiments reported here. Two possibilities exist that cannot be readily differentiated by our findings. One is that platelets themselves may act as inflammatory effector cells in certain circumstances. Thus platelets can release cationic proteins that will bind to GBM and neutralize the anionic charge barrier (reviewed in 47). Platelets also contain proteolytic enzymes including elastase, cathepsins, and collagenase (47) that potentially might degrade GBM through mechanisms similar to those that have been defined in the neutrophil. Platelets also release vasoactive amines, PAF, and thromboxane $\left(\mathrm{TXA}_{2}\right)$; all of these substances have been shown or proposed to participate in various forms of glomerular disease $(36,39,48,49)$. Indeed, perfusion of the renal artery of rabbits with PAF results in a mild increase in protein excretion (50). Finally, studies have demonstrated that mouse platelets are cytotoxic to antibody and C3b-coated sheep erythrocytes through a mechanism that has not been defined (51). However, the hypothesis that the platelet is an inflammatory effector cell does not provide a ready explanation for why tissue injury in this model is equally well prevented by neutrophil depletion (15).

An alternative hypothesis is that platelets are not themselves effector cells but may play an essential role in facilitating the action of neutrophils in mediating glomerular injury. Several observations support this mechanism as a more likely explanation of our findings. Thus, platelets produce various chemotactic substances that can increase neutrophil adherence to damaged endothelial cells, as well as increase neutrophil aggregation, phagocytosis and release of reactive oxygen species and MPO (52-55): The platelet factors responsible for these actions are diverse, but include PAF, TXA, PF4, and platelet derived growth factor (PDGF) $(44,54-55)$. Platelet factor 4 can also potentiate neutrophil elastase action (59). It is noteworthy that pulmonary microvascular injury induced by systemic complement activation is mediated by neutrophils through release of toxic oxygen products $(60)$, and that this lesion can be markedly attenuated by prior depletion of platelets $(9,10)$. Moreover, the release of $\mathrm{O}_{2}^{-}$by rat neutrophils is substantially enhanced by rat platelets, perhaps through platelet release of ATP and/or ADP (55). We have previously provided evidence that reactive oxygen species may participate in producing neutrophil mediated glomerular injury in the model of subendothelial immune complex nephritis studied here via the MPO- $\mathrm{H}_{2} \mathrm{O}_{2}$-halide system (16). Thus, our observation that platelet depletion results in a reduction in protein and fibrin deposition in this neutrophil-mediated model is consistent with the hypothesis that platelets enhance neutrophil-induced glomerular oxidant injury through similar mechanisms.

Our studies also demonstrated that platelets were required for fibrin deposition in this model. Most animal studies of GN have suggested that tissue factor, released by monocytes, is the major stimulus for fibrin deposition (61). Platelets can also increase tissue factor release from endothelial cells in the presence of aggregated IgG (62). Platelets also contain phospholipids that can activate the intrinsic pathway by both Factor XII-dependent and Factor XII-independent pathways (63) as well as directly facilitating Factor Va expression, Factor X activation and prothrombin consumption (reviewed in 64).

In conclusion, we have described a previously unrecognized requirement for platelets in a neutrophil-mediated model of immune complex injury. The mechanism of the augmentation of injury by platelets is unclear but may be critical to many forms of neutrophil-induced tissue injury. The possibility that this interaction exists in human glomerular disease, such as that seen in SLE, remains to be explored.

\section{Acknowledgments}

The authors are grateful to Dr. Seymour Klebanoff for his valuable advice, Ms. Caryl Campbell, Ms. Ann Waltersdorph, Ms. Karen Robbins, and Ms. Stella Chao for technical assistance, and to Ms. Margaret Whitcomb for assistance in preparation of the manuscript.

Support for these studies was provided by grants from the U.S. Public Health Service, DK-34198, DK-39068, and research grants from the Northwest Kidney Foundation and the National Lupus Foundation.

\section{References}

1. Stetson, C. A. 1951. Similarities in the mechanisms determining the Arthus and Shwartzman phenomena. J. Exp. Med. 94:347-358. 
2. Busch, G. J., E. S. Reynolds, E. G. Galvanek, W. E. Braun, and G. J. Dammin. 1971. Human Renal Allografts. The role of vascular injury in early graft failure. Medicine (Baltimore). 50:29-83.

3. Henson, P. M., and C. G. Cochrane. 1969. Immunological induction of increased vascular permeability. J. Exp. Med. 129:153-184.

4. Ward, P. A., and C. G. Cochrane. 1965. Bound complement and immunologic injury of blood vessels. J. Exp. Med. 121:215-233.

5. Margaretten, W., E. L. Howes, and D. G. McKay. 1975. The effect of shock on the inflammatory response. A reevaluation of the role of platelets in the active Arthus reaction. Am. J. Pathol. 78:159170.

6. Margaretten, W., and D. G. McKay. 1969. The role of the platelet in the generalized Shwartzman reaction. J. Exp. Med. 129:585-590.

7. Foker, J. E., D. S. Clark, R. J. Pickering, R. A. Good, and R. L. Varco. 1969. Studies on the mechanisms of canine renal allograft rejection. Transplant. Proc. 1:296-300.

8. Sharma, H. M., S. Moore, H. W. Merrick, and M. R. Smith. 1972. Platelets in early hyperacute allograft rejection in kidneys and their modification by sulfinpyrazone (Anturan) therapy. Am. J. Pathol. 66:445-460.

9. Tvedten, H. W., G. O. Till, and P. A. Ward. 1985. Mediators of lung injury in mice following systemic activation of complement. Am. J. Pathol. 119:92-100.

10. Ward, P. A., G. O. Till, and K. J. Johnson. 1986. Role of platelets in neutrophil dependent, oxygen radical mediated lung injury. Fed. Proc. 45:380. (Abstr.)

11. Matsuo, S., A. Fukatsu, M. L. Taub, P. R. B. Caldwell, J. R. Brentjens, and G. Andres. 1987. Glomerulonephritis induced in the rabbit by antiendothelial antibodies. J. Clin. Invest. 79:1798-1811.

12. Camussi, G., C. Tetta, G. Segoloni, R. Coda, and A. Vercellone. 1982. Localization of neutrophil cationic proteins and loss of anionic charges in glomeruli of patients with systemic lupus erythematosus glomerulonephritis. Clin. Immunol. Immunopathol. 24:299-314.

13. Camussi, G., C. Tetta, G. Mazzucco, G. Monga, C. Roffinello, M. Alberton, P. Dellabona, F. Malavasi, and A. Vercellone. 1986. Platelet cationic proteins are present in glomeruli of lupus nephritis patients. Kidney Int. 39:555-565.

14. Johnson, R. J., W. G. Couser, E. Y. Chi, S. Adler, and S. Klebanoff. 1987. New mechanisms for glomerular injury. Myeloperoxidase-hydrogen peroxide-halide system. J. Clin. Invest. 79:13791387.

15. Johnson, R. J., S. J. Guggenheim, S. J. Klebanoff, R. F. Ochi, A. Wass, P. Baker, M. Schulze, and W. G. Couser. 1988. Morphologic correlates of glomerular oxidant injury induced by the myeloperoxidase-hydrogen peroxide-halide system of the neutrophil. Lab. Invest. 58:294-301.

16. Johnson, R. J., S. J. Klebanoff, R. F. Ochi, S. Adler, P. Baker, L. Sparks, and W. G. Couser. 1987. Participation of the myeloperoxidase- $\mathrm{H}_{2} \mathrm{O}_{2}$-halide system in immune complex nephritis. Kidney Int. 32:342-349.

17. Golbus, S. M., and C. B. Wilson. 1979. Experimental glomerulonephritis induced by in situ formation of immune complexes in glomerular capillary wall. Kidney Int. 16:148-157.

18. Steinbuch, M., and R. Audran. 1969. The isolation of IgG from mammalian sera with aid of caprylic acid. Arch. Biochem. Biophys. 134:279-284.

19. Lavelle, K. J., and A. M. Moseman. 1978. The influence of selective thrombocytopenia on immune complex glomerulonephritis. J. Lab. Clin. Med. 92:737-749.

20. Holdsworth, S. R., T. J. Neale, and C. B. Wilson. 1981. Abrogation of macrophage dependent injury in experimental glomerulonephritis in the rabbit. J. Clin. Invest. 68:686-698.

21. Doumas, B. T., W. A. Watson, and H. G. Biggs. 1971. Albumin standards and the measurement of serum albumin with bromcresol green. Clin. Chim. Acta. 31:87-96.

22. Mancini, O., O. Carbonara, and J. R. Heremans. 1965. Immu- nochemical quantitation of antigens by single radial immunodiffusion. Immunochemistry. 2:235-254.

23. Gewurz, H., and L. A. Suyekira. 1976. Complement. In Manual of Clinical Immunology. N. R. Rose and H. Friedman, editors. American Society for Microbiology, Washington, D.C. p. 36.

24. Bradley, G. M., and E. S. Benson. 1974. Examination of the urine. In Todd-Sanford Clinical Diagnosis by Laboratory Methods. I. Davidson, and J. B. Henry, editors. 15th ed. W. B. Saunders, Philadelphia.

25. Salant, D. J., A. V. Cybulsky, and I. D. Feintzeig. 1986. Quantitation of exogenous and endogenous components of glomerular immune deposits. Kidney Int. 30:255-263.

26. Salant, D. J., C. Darby, and W. G. Couser. 1980. Experimental membranous glomerulonephritis in rats. Quantitative studies of glomerular immune deposit formation in isolated glomeruli and whole animals. J. Clin. Invest. 66:71-81.

27. Strassberg, J., J. Paule, H. C. C. Gonick, M. H. Maxwell, and C. R. Kleeman. 1967. The quantitative estimation of perfusible glomeruli and the collagen and non-collagen nitrogen of the normal kidney. Nephron. 4:384-393.

28. Couser, W. G., J. R. Hoyer, N. B. Jermanovich, S. Belok, and M. M. Stilmant. 1978. Effect of aminonucleoside nephrosis on immune complex localization in autologous immune complex nephropathy in rats. J. Clin. Invest. 61:561-572.

29. Beyer, W. H., editor. 1976. Handbook of Tables for Probability and Statistics. 2nd ed. Chemical Rubber Co., Cleveland, OH. 642.

30. Garcia, D. L., S. Anderson, K. J. Sandquist, H. G. Rennke, and B. M. Brenner. 1988. Anemia lessens systemic/glomerular hypertension and proteinuria in renal ablation. Kidney Int. 33:375. (Abstr.)

31. Barratt, T. M., P. N. McLaine, and J. F. Soothill. 1979. Albumin excretion as a measure of glomerular dysfunction in children. Arch. Dis. Child. 45:496-501.

32. Camussi, G., C. Tetta, M. Meroni, L. Torri-Tarelli, C. Roffinello, A. Alberton, C. Deregibus, and A. Sessa. 1986. Localization of cationic proteins derived from platelets and polymorphonuclear neutrophils and local loss of anionic sites in glomeruli of rabbits with experimentally induced acute serum sickness. Lab. Invest. 55:56-62.

33. Miller, K., I. G. Dresner, and A. F. Michael. 1980. Localization of platelet antigens in human kidney disease. Kidney Int. 18:472-479.

34. Parbtani, A., G. Frampton, Y. Yewdall, N. Kasai, and J. S. Cameron. 1980. Platelet and plasma serotonin in glomerulonephritis III: The nephritis of systemic lupus erythematosus. Clin. Nephrol. 14:164-172.

35. Izumino, K., H. Iida, M. Asaka, M. Fujita, and S. Sasayama. 1987. Effect of the antiplatelet agents, ticlopidine and dipyridamole on nephrotoxic serum nephritis in rats. 10th International Congress of Nephrology, London, England, July 1987. pp 333. (Abstr.)

36. Koyama, A., H. Inage, M. Sano, M. Narita, S. Tojo, G. H. Neild, and J. S. Cameron. 1985. Platelet involvement in the nephritis of acute serum sickness in rabbits: protection by dipyridamole and FUT-175. Clin. Exp. Immunol. 61:388-396.

37. Donadio, J. V., C. F. Anderson, J. C. Mitchell, K. E. Holley, D. M. Ilstrup, V. Fuster, and J. H. Chesebro. 1984. Membranoproliferative glomerulonephritis. A prospective clinical trial of platelet-inhibitor therapy. N. Engl. J. Med. 310:1421-1426.

38. Ueda, N., S. Kawaguchi, Y. Niinomi, T. Nonoda, M. Ohnishi, S. Ito, and T. Yasaki. 1986. Effect of dipyridamole treatment of proteinuria in pediatric renal disease. Nephron. 44:174-179.

39. Kniker, W. T., and C. G. Cochrane. 1968. The localization of circulating immune complexes in experimental serum sickness. $J$. Exp. Med. 127:119-135.

40. Lavelle, K. J., B. A. Ransdell, and S. A. Kleit. 1976. The influence of selective thrombocytopenia on nephrotoxic nephritis. $J$. Lab. Clin. Med. 87:967-975.

41. Sindrey, M., T. L. Marshall, and P. Naish. 1979. Quantitative assessment of the effects of platelet depletion in the autologous phase of nephrotoxic serum nephritis. Clin. Exp. Immunol. 36:90-96. 
42. Salant, D. J., S. Adler, C. Darby, N. J. Capparill, G. C. Groggel, I. D. Feintzer, H. G. Rennke, and J. E. Ditmer. 1985. Influence of antigen distribution on the mediation of immunological glomerular injury. Kidney Int. 27:938-950.

43. Camussi, G., I. Pawlowski, F. Bussolino, P. R. B. Caldwell, J. Brentjens, and G. Andres. 1983. Release of platelet activating factor in rabbits with antibody-mediated injury of the lung: the role of leukocytes and of pulmonary endothelial cells. J. Immunol. 131:1802-1807.

44. Schlondorff, D., and R. Neuwirth. 1986. Platelet-activating factor and the kidney. Am. J. Physiol. 251:F1-F11.

45. Legrand, Y. J., F. Fauvel, B. Arbeille, D. Leger, H. Mouhli, N. Gutman, and J. P. Muh. 1986. Activation of platelets by microfibrils and collagen. A comparative study. Lab. Invest. 54:566-573.

46. Henson, P. M., and M. H. Ginsberg. 1981. Immunological reactions of platelets. In Platelets in Biology and Pathology-2. J. L. Gordon, editor. Elsevier/North-Holland Biomedical Press, New York. 265-308.

47. Barnes, J. L., and M. A. Venkatachalam. 1985. The role of platelets and polycationic mediators in glomerular vascular injury. Semin. Nephrol. 5:57-68.

48. Bertani, T., A. Benigni, F. Cutillo, G. Rocchi, C. Morelli, C. Carminati, P. Verroust, and G. Remuzzi. 1986. Effect of aspirin and sulindac in rabbit nephrotoxic nephritis. J. Lab. Clin. Med. 107:261268.

49. Camussi, G., I. Pawlowski, R. Saunders, J. Brentjens, and G. Andres. 1987. Receptor antagonist of platelet activating factor inhibits inflammatory injury induced by in situ formation of immune complexes in renal glomeruli and in the skin. J. Lab. Clin. Med. 110:196206.

50. Camussi, G., C. Tetta, R. Coda, G. P. Segoloni, and A. Vercellone. 1984. Platelet-activating factor-induced loss of glomerular anionic charges. Kidney Int. 25:73-81.

51. Slezak, S., D. E. Symer, and H. S. Shin. 1987. Platelet-mediated cytotoxicity. Role of antibody and C3, and localization of the cytotoxic system in membranes. J. Exp. Med. 166:489-505.

52. Boogaerts, M. A., O. Yamada, H. S. Jacob, and C. F. Moldow. 1982. Enhancement of granulocyte-endothelial cell adherence and granulocyte-induced cytotoxicity by platelet release products. Proc. Natl. Acad. Sci. USA. 79:7019-7023.
53. Redl, H., D. E. Hammerschmidt, and G. Schlag. 1983. Augmentation by platelets of granulocyte aggregation in response to chemotaxins: Studies utilizing an improved cell preparation technique. Blood. 61:125-131.

54. Sakamoto, H., and A. Ooshima. 1985. Activation of neutrophil phagocytosis of complement coated and IgG coated sheep erythrocytes by platelet release products. Br. J. Hematol. 60:173-181.

55. McCulloch, K. K., J. Powell, K. J. Johnson, and P. A. Ward. 1986. Enhancement by platelets of oxygen radical responses of human neutrophils. Fed. Proc. 45:682. (Abstr.)

56. Spagnuolo, P. J., J. J. Ellner, A. Hassid, and M. J. Dunn. 1980. Thromboxane $\mathrm{A}_{2}$ mediates augmented polymorphonuclear leukocyte adhesiveness. J. Clin. Invest. 66:406-414.

57. Deuel, T. F., R. M. Senior, J. S. Huang, and G. L. Griffin. 1982. Chemotaxis of monocytes and neutrophils to platelet-derived growth factor. J. Clin. Invest. 69:1046-1049.

58. Deuel, T. F., R. M. Senior, D. Chang, G. L. Griffin, R. L. Heinrikson, and E. T. Kaiser. 1981. Platelet factor 4 is chemotactic for neutrophils and monocytes. Proc. Natl. Acad. Sci. USA. 78:45844587.

59. Lonky, S. A., and H. Wohl. 1981. Stimulation of human leukocyte elastase by platelet factor 4. J. Clin. Invest. 67:817-826.

60. Ward, P. A., G. O. Till, R. Kunkel, and C. Beauchamp. 1983. Evidence for role of hydroxyl radical in complement and neutrophildependent tissue injury. J. Clin. Invest. 72:789-801.

61. Tipping, P. G., L. A. Worthington, and S. R. Holdsworth. 1987. Quantitation and characterization of glomerular procoagulant activity in experimental glomerulonephritis. Lab. Invest. 56:155-159.

62. Tannenbaum, S. H., R. Finko, and D. B. Cines. 1986. Antibody and immune complexes induce tissue factor production by human endothelial cells. J. Immunol. 137:1532-1537.

63. Walsh, P. N., and J. H. Griffin. 1981. Contributions of human platelets to the proteolytic activation of blood coagulation factors XII and XI. Blood. 57:106-118.

64. Majerus, P. W., J. P. Miletich, W. H. Kane, S. L. Hoffmann, N. Stanford, and C. M. Jackson. 1980. The formation of thrombin on the platelet surface. In The Regulation of Coagulation. K. G. Mann and F. B. Taylor, editors. Elsevier/North Holland, New York. 215-221. 